\title{
Examining the safety of colon anastomosis on a rat model of ischemia-reperfusion injury
}

\author{
David Czeiger ${ }^{1}$, Anton Osyntsov², Lidia Osyntsov ${ }^{3}$, Chad G Ball ${ }^{4}$, Roy Gigi ${ }^{5}$ and Gad Shaked ${ }^{1,2^{*}}$
}

\begin{abstract}
Introduction: Intestinal ischemia and reperfusion can impair anastomotic strength. The purpose of this study was to evaluate the safety of delayed colon anastomosis following remote ischemia-reperfusion (IR) injury.

Methods: Rats divided into two groups underwent bilateral groin incisions, however only the study group had femoral artery clamping to inflict IR injury. Twenty-four hours following this insult, the animals underwent laparotomy, incision of the transverse colon and reanastomosis. End points included anastomotic leakage, strength and histopathological features.

Results: Anastomotic leak among IR animals (22.2\%) was not statistically different in comparison to the controls $[10.5 \%(p=0.40)]$. Anastomotic mean burst pressures showed no statistically significant difference [150.6 \pm $15.57 \mathrm{mmHg}$ in the control group vs. $159.9 \pm 9.88 \mathrm{mmHg}$ in the IR group $(p=0.64)]$. The acute inflammatory process in the IR group was similar to controls $(p=0.26)$, as was the chronic repair process $(p=0.88)$. There was no significant difference between the inflammation:repair ratios amongst the two groups $(p=0.67)$.
\end{abstract}

Conclusion: Primary colon repair is safe when performed 24 hours following systemic IR injury.

Keywords: Ischemia-reperfusion, Injury, Colon, Intestinal anastomosis, Rat model, Emergency surgery

\section{Introduction}

Ischemia-reperfusion (IR) injury represents a fundamental common pathway of tissue damage in a wide variety of disease and surgical processes such as major trauma, acute mesenteric ischemia, septic and hypovolemic shock, abdominal aortic aneurism surgery, and cardiopulmonary bypass $[1,2]$. Interruption of blood supply results in ischemic injury to all body systems and especially to high metabolically active tissues; the intestine is a prominent example of a sensitive tissue to IR injury which is associated with high morbidity and mortality [1]. Paradoxically, restoration of blood flow to the ischemic tissue augments cell injury by delivering toxic mediators induced in the ischemic tissue into the circulation thus affecting distant organs. This might lead to the development of systemic inflammatory response syndrome, which can progress to multiple organ

\footnotetext{
* Correspondence: shakedg@bgu.ac.il

'Department of General Surgery and Trauma Unit, Soroka University Medical Center and Ben-Gurion University, Beer Sheva, Israel

${ }^{2}$ Department of General Surgery, Soroka University Medical Center and BenGurion University, Beer Sheva 84101, Israel

Full list of author information is available at the end of the article
}

failure and death [2]. Among the toxic mediators produced in the IR injured tissue are acute-phase proteins, proinflammatory cytokines, oxygen free radicals, and components of the complement system [3]. Emergency surgery and trauma situations may require abbreviated procedures during the initial phase of shock and organ ischemia. Definitive procedures including anastomosis to restore bowel continuity are undertaken 24 hours or more afterward. Two common examples of such situations are the strategy of damage control surgery in seriously injured patients, and acute mesenteric ischemia. In damage control laparotomy the goal in the emergency surgery is to stop bleeding and to control spillage from the intestine. In the second operation, which is done after the patient's deranged physiology is corrected, bowel anastomosis may be created. In mesenteric ischemia gangrenous segments of the bowel are resected, while fluid resuscitation continues. Not infrequently, the patient condition does not allow performing primary anastomosis. This may be done during a second look operation 24 hours later. The spectrum of the effects of IR injury on the intestine is broad and ranges from a 
transient absorptive impair following mucosal damage to frank gangrene of the bowel [4]. Previous reports have shown that ischemia and reperfusion of the intestinal wall can lead to impaired anastomotic strength [5-8]. However, there is not enough evidence in the literature to show the safety of delayed bowel anastomosis following systemic IR injury. We hypothesized that IR injury would adversely affect the safety of colonic anastomoses performed 24 hours following the injury. To evaluate this hypothesis we investigated the effects of IR injury on the healing of colon anastomoses in a rat model.

\section{Materials and methods}

The protocol employed in this study was approved by the Committee for the Ethical Care and Use of Laboratory Animals of the Ben-Gurion University of the Negev (approval code IL-41-7-2006). It included a provision that any rat exhibiting evidence of distress (such as restlessness or aggressive behavior) be immediately euthanized. Rats were acclimated to the laboratory for 2 weeks prior to the study and had free access to water and food at all times. A total of 40 male Sprague-Dawley rats (average weight $350 \mathrm{~g}$ ) were used. The number of animals in each group was considered satisfactory based on a two-sided sample size determination (power analysis), assuming power of 0.80 and significance of 0.05 . All rats were anesthetized with inhaled isoflurane $1 \%$ at a rate of $3-5 \mathrm{~L} / \mathrm{min}$. The study group $(\mathrm{n}=20)$ underwent bilateral groin incision and clamping the femoral arteries for 30 minutes. The control group $(n=20)$ had a similar sham operation without inducing extremities ischemia. All wounds were then sutured with $4 / 0$ silk. Twenty-four hours following this insult, all animals were anesthetized and underwent a midline laparotomy, full circumference incision of the transverse colon (including resection of $0.5 \mathrm{~cm}$ of mesentery on each side of the colon) and reanastomosis (end-to-end) using 4/0 polyglycolic acid sutures. The animals were then followed up and sacrificed one week later. The peritoneal cavity was subsequently explored for the presence of perforation, and local or generalized peritonitis.

Anastomotic healing was assessed by determining anastomotic burst pressures, as well as by formal histopathological examination. The transverse colon was dissected free of adhesions and resected. One end of this segment was ligated, and a catheter connected to a sphygmomanometer was secured to the other end. Air was then pumped into the segment of colon, which was submerged in water. Intraluminal pressure was monitored continuously while the air was injected. The intraluminal pressure at which air leakage from the anastomosis occurred was recorded as the burst pressure. More specifically, this parameter represents the mechanical strength of the anastomosis. The colon specimen was then processed and evaluated for three parameters of acute inflammation: (1) total number of polymorphonuclear cells, (2) total number of red blood cells and (3) the amount of fibrin, as well as for three parameters of chronic wound healing: (1) total number of mononuclear cells, (2) total number of fibroblasts and (3) total amount of collagen. Each parameter was graded from 0 to 4 . The colon surgeon and the pathologist were each blinded with regard to the individual group allocation history of the animals. Statistical analysis was performed using GraphPad Prism version 4.00 for Windows, GraphPad Software, San Diego, California, USA. Parametric results are expressed as mean \pm SEM and were compared using an unpaired t-test. Two-tailed $\mathrm{p}<$ 0.05 was considered as having a statistical significance.

\section{Results}

Three animals were excluded from the study because they died before the completion of the surgical procedure (1 control and 2 IR). One rat in the IR group also died during the 7-day follow-up period ( $p>0.05$ ). Autopsy of this animal revealed an anastomotic leak and diffuse peritonitis. Among the animals that completed the follow-up period, anastomotic leak and a severe peritoneal reaction was observed in 3 animals within the IR cohort, and in 2 control animals. The anastomotic leak rate among IR animals $(22.2 \%)$ was not statistically different in comparison to the controls $[10.5 \%(\mathrm{p}=0.40)]$. The anastomotic mean burst pressures also showed no statistically significant difference $[150.6 \pm 15.57 \mathrm{mmHg}$ in the control group vs. $159.9 \pm 9.88 \mathrm{mmHg}$ in the IR group $(\mathrm{p}=0.64)]$. The specific distribution of individual burst pressures is displayed in Figure 1. More specifically, the burst pressures among the IR group display significantly less variance than the control group. The $\mathrm{F}$ test used to compare variances shows a significant difference $(\mathrm{p}=0.025)$. To statistically compare histopathological results, 3 grades were assigned for both the inflammatory process and chronic repair process for each animal. Student's t-test comparing the means of sums and Fisher's exact test comparing inflammation:repair ratios of the two groups revealed no significant statistical differences. The acute inflammatory process in the IR group was similar to controls $(\mathrm{p}=0.26)$, as was the chronic repair process $(\mathrm{p}=0.88)$. There was also no significant difference between the inflammation:repair ratios in the two groups $(\mathrm{p}=0.67)$.

\section{Discussion}

The goal of this study was to examine the safety of colon anastomosis performed 24 hours after profound systemic ischemia-reperfusion injury. Our results show that resection and anastomosis of the colon is safe, when performed twenty-four hours following profound, remote IR injury. This is based on similar mortality and anastomotic leak ratios (although a non-significant trend towards a higher incidence of anastomotic leak among the IR animals was 


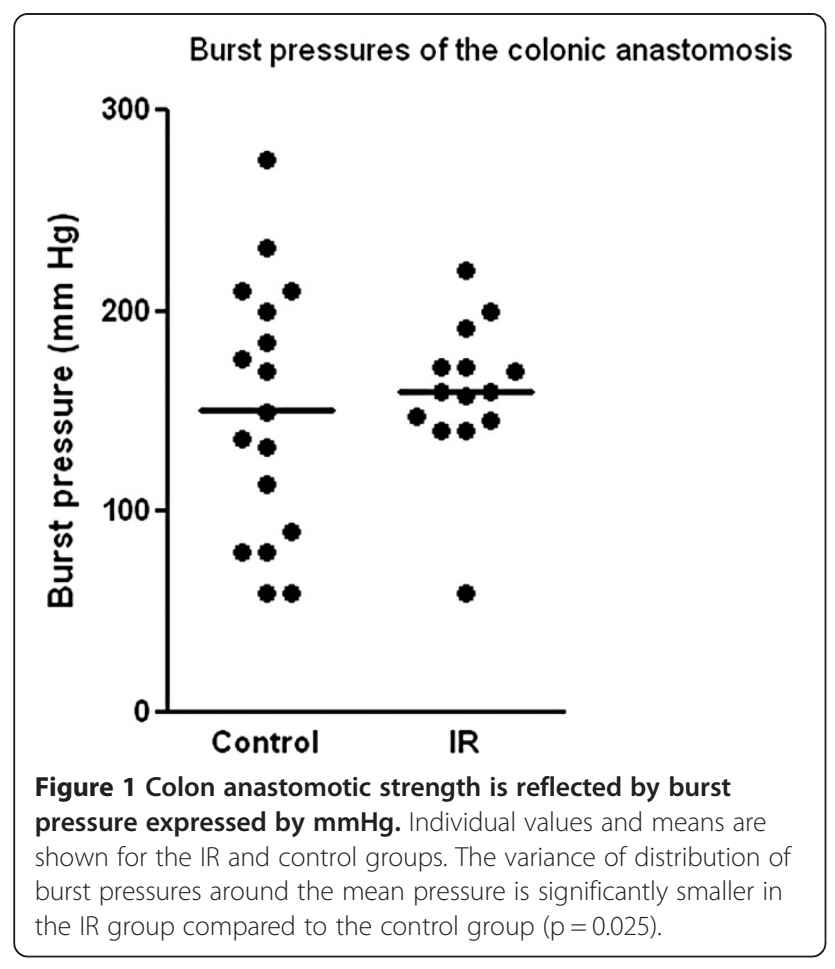

noted), comparable anastomotic mechanical strengths, and equivalent histological features of the anastomosis between the IR and the control groups.

Today, in 2013, anastomotic leak after colorectal resection still has lethality of $6-22 \%$ and morbidity leading to reoperation and permanent stoma in 56\% [9]. There is convincing evidence in the literature that primary repair or anastomosis is appropriate for the management of most colonic injuries and for other emergent surgical situations [10-17]. In contrast, there is little methodologically sound evidence outlining the outcome of a colon anastomosis in the setup of severe IR. Damage control surgery (DCS) is probably one of the most common situations where the surgeon faces the dilemma of creating colonic anastomosis in a delayed fashion after IR injury. Clinical retrospective series have revealed contradictory conclusions regarding the safety of this procedure. Miller et al. [18] concluded that delayed anastomoses in patients undergoing DCS is safe, whereas Weinberg and colleagues reported a significant colon related complication rate in patients who were treated by resection and anastomosis [19]. A third group also identified a higher incidence of colonic anastomotic leakage among DCS patients who had resection followed by anastomosis; however they declared that resection and anastomosis is still considered safe [20]. Ott pointed in a recently published manuscript that colon anastomosis is safe unless the abdomen remains open. He also regards the left colon as more vulnerable to leak under these conditions [21]. It is obvious that limitations in these studies include heterogeneous patient populations, variance in patients' clinical condition and surgeons' preference, and even the very definition of DCS by different surgeons.

To overcome these limitations inherent in clinical retrospective studies we created a rat model of IR injury followed by resection and reansatomosis of the transverse colon. IR injury has been intensively investigated since the 1970s. The IR phenomenon represents the common underlying pathophysiological process to a variety of medical conditions and surgical procedures. Tissue ischemia with inadequate oxygen supply followed by successful reperfusion initiates a wide and complex array of inflammatory responses that may both aggravate local injury, as well as induce impairment of remote organ function [22]. Review of the literature reveals experimental studies evaluating the effect of transient preoperative IR on gut anastomotic strength $[6,8,23-29]$. The results of these studies were equivocal. This may partially be explained by the degree and duration of the inflicted ischemia [26]. Also, the surgical procedure was done on small bowel in some of the studies [30], while in others large bowel anastomoses were tested [31]. Furthermore, in the previous models the ischemia was done by clamping the blood supply of the resected segment of intestine, and/or performed the intestinal anastomosis immediately following the IR injury. Kuzu et al. attempted to demonstrate the systemic nature of IR by occluding the superior mesenteric artery and its collaterals and immediately thereafter they resected and reansatomose the left colon [7]. Posma described the effect of a prolonged interval between IR and anastomotic construction on the anastomosis healing, but used a model of local mesenteric ischemia [26].

We believe that the present model, with severe systemic remote ischemia, performance of a colon anastomosis 24 hours later, and testing the anastomotic strength after one week, more closely resembles the true conditions of some emergent conditions that the surgical approach for them is still uncertain. Several mechanisms have been suggested to explain the blunting of the IR deleterious effect on bowel anastomoses when these are constructed late after the insult. One is subsidence of the harmful effects over the time elapsed from the insult to the creation of the anastomosis. Another explanation is the protective effect of ischemic preconditioning [30,32]. Recently, studies have been published on prevention/alleviation the effect of IR injury by inhibiting compliment system activation [33], by applying antioxidants [34,35], and trace elements [36]. Another trend for attenuating effects of IR injury is ischemic postconditioning [37-39].

In our experiment we amplified the local ischemia at the site of anastomosis by resecting $0.5 \mathrm{~cm}$ of mesentery on each side of the divided transverse colon. Even under these stringent conditions we did not observe the expected IR harmful effects. On the other hand, our 
results showed no benefit to the ischemic group. This should question the protective effect of ischemic preconditioning in this setup.

In summary, this rat model augments the literature which support delayed primary repair after ischemiareperfusion injury. However, more laboratory and clinical evidence is required before final conclusion can be drawn. More studies are also needed to understand the attenuation of the harmful effects of IR on intestinal anastomosis when performed 24 hours after the injury.

\section{Competing interests}

The authors declare that they have no competing interests.

\section{Authors' contributions}

DC participated in the design of the study, performed the statistical analysis, and revised the manuscript, $\mathrm{AO}$ carried out the operations, LO performed the pathological examinations and the evaluations of the specimens, CB was involved in drafting the manuscript and revising it critically, RG participated in the laboratory work and animal assays, GS initiate the study, created its design and wrote the manuscript. All authors read and approved the final manuscript.

\section{Acknowledgements}

This work was not supported by any third party such as pharmaceutical or industrial company, or grants. No author has conflict of interest regarding the publication of this work. The study has not been presented, yet, at a scientific or medical conference.

The manuscript is not under consideration for publication by any other journal.

\section{Author details}

${ }^{1}$ Department of General Surgery and Trauma Unit, Soroka University Medical Center and Ben-Gurion University, Beer Sheva, Israel. 'Department of General Surgery, Soroka University Medical Center and Ben-Gurion University, Beer Sheva 84101, Israel. ${ }^{3}$ Pathology Institute, Soroka University Medical Center and Ben- Gurion University, Beer Sheva, Israel. ${ }^{4}$ Department of Surgery, University of Calgary, Calgary, Alberta, Canada. ${ }^{5}$ Department of Orthopedics, Tel Aviv Sourasky Medical Center, Tel Aviv, Israel.

Received: 19 April 2013 Accepted: 27 June 2013

Published: 2 July 2013

\section{References}

1. Mallick $H_{\text {, }}$, Yang W, Winslet MC, Seifalian AM: Ischemia-reperfusion injury of the intestine and protective strategies against injury. Dig Dis Sci 2004, 49(9):1359-1377.

2. Leng $Y F$, Zhang $Y$, Zhang $Y, X u e X$, Wang $T$, Kang $Y Q$ : Ischemic postconditioning attenuates the intestinal injury induced by limb ischemia/ reperfusion in rats. Braz J Med Biol Res 2011, 44(5):411-417.

3. Grootjans J, Lenaerts K, Derikx JP, Matthijsen RA, de Bruine AP, van Bijnen $A A$, van Dam RM, Dejong CH, Buurman WA: Human intestinal ischemiareperfusion-induced inflammation characterized: experiences from a new translational model. Am J Pathol 2010, 176(5):2283-2291.

4. Haglund U, Bulkley GB, Granger DN: On the pathophysiology of intestinal ischemic injury. Clinical review. Acta Chir Scand 1987, 153(5-6):321-324.

5. Posma LA, Bleichrodt RP, Lomme RM, de Man BM, van Goor H, Hendriks T: Early anastomotic repair in the rat intestine is affected by transient preoperative mesenteric ischemia. J Gastrointest Surg 2009, 13(6):1099-1106.

6. Kologlu M, Yorganci K, Renda N, Sayek I: Effect of local and remote ischemia-reperfusion injury on healing of colonic anastomoses. Surgery 2000, 128(1):99-104.

7. Kuzu MA, Tanik A, Kale IT, Aslar AK, Koksoy C, Terzi C: Effect of ischemia/ reperfusion as a systemic phenomenon on anastomotic healing in the left colon. World J Surg 2000, 24(8):990-994.

8. Posma LA, Bleichrodt RP, van Goor H, Hendriks T: Transient profound mesenteric ischemia strongly affects the strength of intestinal anastomoses in the rat. Dis Colon Rectum 2007, 50(7):1070-1079.
9. Daams F, Luyer M, Lange JF: Colorectal anastomotic leakage: aspects of prevention, detection and treatment. World J Gastroenterol 2013, 19(15):2293-2297.

10. Demetriades D, Murray JA, Chan L, Ordonez C, Bowley D, Nagy KK, Cornwell EE 3rd, Velmahos GC, Munoz N, Hatzitheofilou C, Schwab CW, Rodriguez A, Cornejo C, Davis KA, Namias N, Wisner DH, Ivatury RR, Moore EE, Acosta JA, Maull Kl, Thomason MH, Spain DA, Committee on Multicenter Clinical Trials, American Association for the Surgery of Trauma: Penetrating colon injuries requiring resection: diversion or primary anastomosis? An AAST prospective multicenter study. J Trauma 2001, 50(5):765-775.

11. Gonzalez RP, Merlotti GJ, Holevar MR: Colostomy in penetrating colon injury: is it necessary? J Trauma 1996, 41(2):271-275.

12. Sasaki LS, Allaben RD, Golwala R, Mittal VK: Primary repair of colon injuries: a prospective randomized study. J Trauma 1995, 39(5):895-901.

13. Stone HH, Fabian TC: Management of perforating colon trauma: randomization between primary closure and exteriorization. Ann Surg 1979, 190(4):430-436.

14. Chappuis CW, Frey DJ, Dietzen CD, Panetta TP, Buechter KJ, Cohn I Jr: Management of penetrating colon injuries. A prospective randomized trial. Ann Surg 1991, 213(5):492-497. discussion 497-8.

15. Singer MA, Nelson RL: Primary repair of penetrating colon injuries: a systematic review. Dis Colon Rectum 2002, 45(12):1579-1587.

16. Jimenez Fuertes $M$, Costa Navarro D: Resection and primary anastomosis without diverting ileostomy for left colon emergencies: is it a safe procedure? World J Surg 2012, 36(5):1148-1153.

17. Constantinides VA, Tekkis PP, Athanasiou T, Aziz O, Purkayastha S, Remzi FH, Fazio WW, Aydin N, Darzi A, Senapati A: Primary resection with anastomosis vs. Hartmann's procedure in nonelective surgery for acute colonic diverticulitis: a systematic review. Dis Colon Rectum 2006, 49(7):966-981.

18. Miller PR, Chang MC, Hoth JJ, Holmes JH 4th, Meredith JW: Colonic resection in the setting of damage control laparotomy: is delayed anastomosis safe? Am Surg 2007, 73(6):606-609. discussion 609-10.

19. Weinberg JA, Griffin RL, Vandromme MJ, Melton SM, George RL, Reiff DA, Kerby $J D$, Rue LW: Management of colon wounds in the setting of damage control laparotomy: a cautionary tale. J Trauma 2009, 67(5):929-935.

20. Kashuk JL, Cothren CC, Moore EE, Johnson JL, Biffl WL, Barnett CC: Primary repair of civilian colon injuries is safe in the damage control scenario. Surgery 2009, 146(4):663-668. discussion 668-70.

21. Ott MM, Norris PR, Diaz JJ, Collier BR, Jenkins JM, Gunter OL, Morris JA Jr: Colon anastomosis after damage control laparotomy: recommendations from 174 trauma colectomies. J Trauma 2011, 70(3):595-602.

22. Collard CD, Gelman S: Pathophysiology, clinical manifestations, and prevention of ischemia-reperfusion injury. Anesthesiology 2001, 94(6):1133-1138.

23. Aydin C, Teke Z, Aytekin F, Yenisey C, Kabay B, Simsek NG, Tekin K: Tempol prevents harmful effects of remote ischemia reperfusion injury on healing of experimental colonic anastomoses. Int J Colorectal Dis 2007, 22(3):325-331.

24. Colak T, Turkmenoglu O, Dag A, Polat A, Comelekoglu U, Bagdatoglu O, Polat G, Kanik A, Akca T, Aydin S: The effect of remote ischemic preconditioning on healing of colonic anastomoses. J Surg Res 2007, 143(2):200-205.

25. Murthy S, Hui-Qi Q, Sakai T, Depace DE, Fondacaro JD: Ischemia/ reperfusion injury in the rat colon. Inflammation 1997, 21(2):173-190.

26. Posma LA, Bleichrodt RP, van Goor H, Hendriks T: A prolonged interval between deep intestinal ischemia and anastomotic construction does not impair wound strength in the rat. Int J Colorectal Dis 2007, 22(12):1485-1491.

27. Posma LA, Bleichrodt RP, van Goor H, Hendriks T: Ischemia and prolonged reperfusion before anastomotic construction do not reduce wound strength in the rat intestine. Surgery 2006, 139(5):671-677.

28. Rolim MF, Riger CJ, Eleutherio EC, Colao Cda F, Pereira GC, Schanaider A: Colonic healing after portal ischemia and reperfusion: an experimental study with oxidative stress biomarkers. Redox Rep 2007, 12(6):267-274.

29. Teke Z, Aytekin FO, Kabay B, Yenisey C, Aydin C, Tekin K, Sacar M, Ozden A: Pyrrolidine dithiocarbamate prevents deleterious effects of remote ischemia/reperfusion injury on healing of colonic anastomoses in rats. World J Surg 2007, 31(9):1835-1842.

30. Holzner PA, Kulemann B, Kuesters S, Timme S, Hoeppner J, Hopt UT, Marjanovic G: Impact of remote ischemic preconditioning on wound healing in small bowel anastomoses. World J Gastroenterol 2011, 17(10):1308-1316. 
31. Kosmidis C, Efthimiadis C, Anthimidis G, Basdanis G, Apostolidis S, Hytiroglou P, Vasiliadou K, Prousalidis J, Fahantidis E: Myofibroblasts and colonic anastomosis healing in Wistar rats. BMC Surg 2011, 11:6-2482-11-6.

32. Moore-Olufemi SD, Kozar RA, Moore FA, Sato N, Hassoun HT, Cox CS Jr, Kone $\mathrm{BC}$ : Ischemic preconditioning protects against gut dysfunction and mucosal injury after ischemia/reperfusion injury. Shock 2005, 23(3):258-263.

33. Diepenhorst GM, van Gulik TM, Hack CE: Complement-mediated ischemiareperfusion injury: lessons learned from animal and clinical studies. Ann Surg 2009, 249(6):889-899.

34. Kabali B, Girgin S, Gedik E, Ozturk H, Kale E, Buyukbayram H: N-acetylcysteine prevents deleterious effects of ischemia/reperfusion injury on healing of colonic anastomosis in rats. Eur Surg Res 2009, 43(1):8-12.

35. Teke Z, Bostanci EB, Yenisey C, Sacar M, Simsek NG, Akoglu M: Caffeic acid phenethyl ester alleviates mesenteric ischemia/reperfusion injury. J Invest Surg 2012, 25(6):354-365.

36. Ersoy YE, Ayan F, Himmetoglu S: Trace element levels in ischemiareperfusion injury after left colonic anastomosis in rats and effects of papaverine and pentoxiphylline on vascular endothelial growth factor in anastomosis healing. Acta Gastroenterol Belg 2011, 74(1):22-27.

37. Chu WW, Nie L, He XY, Yan AL, Zhou Y, Wu GL, Wang DH: Change of cytochrome $\mathrm{c}$ in postconditioning attenuating ischemia-reperfusion-induced mucosal apoptosis in rat intestine. Sheng Li Xue Bao 2010, 62(2):143-148.

38. Wen SH, Li Y, Li C, Xia ZQ, Liu WF, Zhang XY, Lei WL, Huang WQ, Liu KX: Ischemic postconditioning during reperfusion attenuates intestinal injury and mucosal cell apoptosis by inhibiting JAK/STAT signaling activation. Shock 2012, 38(4):411-419.

39. Wen SH, Ling YH, Li Y, Li C, Liu JX, Li YS, Yao X, Xia ZQ, Liu KX: Ischemic postconditioning during reperfusion attenuates oxidative stress and intestinal mucosal apoptosis induced by intestinal ischemia/reperfusion via aldose reductase. Surgery 2013, 153(4):555-564.

doi:10.1186/1749-7922-8-24

Cite this article as: Czeiger et al:: Examining the safety of colon anastomosis on a rat model of ischemia-reperfusion injury. World Journal of Emergency Surgery 2013 8:24.

\section{Submit your next manuscript to BioMed Central and take full advantage of:}

- Convenient online submission

- Thorough peer review

- No space constraints or color figure charges

- Immediate publication on acceptance

- Inclusion in PubMed, CAS, Scopus and Google Scholar

- Research which is freely available for redistribution 